\title{
A new model of the carbonator reactor in the Calcium Looping technology for post-combustion $\mathrm{CO}_{2}$ capture
}

\author{
C. Ortiz ${ }^{\mathrm{a}}$, R. Chacartegui ${ }^{\mathrm{a}, *}$, J.M. Valverde ${ }^{\mathrm{b}}$, J.A. Becerra ${ }^{\mathrm{a}}$, L. A. Perez-Maquedac
}

${ }^{a}$ Energy Engineering Department, University of Seville, Camino de los descubrimientos s/n, 41092 Sevilla, Spain ${ }^{b}$ Faculty of Physics, University of Seville, Avenida Reina Mercedes s/n, 41012 Sevilla, Spain

'Instituto de Ciencia de Materiales de Sevilla (C.S.I.C.- Univ. Sevilla), Americo Vespucio 49, 41092 Sevilla, Spain

* Corresponding author. Tel.: +34 954487615.

E-mail address: ricardoch@us.es

\begin{abstract}
The Ca-Looping (CaL) process is considered as a promising technology for $\mathrm{CO}_{2}$ post-combustion capture in power generation plants yielding a minor penalty on plant performance as compared with other capture technologies such as conventional amine-based capture systems. This manuscript presents a new carbonator reactor model based on lab-scale multicyclic $\mathrm{CaO}$ conversion results, which take into account realistic $\mathrm{CaO}$ regeneration conditions that necessarily involve calcination under high $\mathrm{CO}_{2}$ partial pressure and high temperature. Under these conditions, $\mathrm{CaO}$ conversion in the diffusion controlled stage is a relevant contribution to the carbonation degree in the typical residence times. The main novelty of the model proposed in the present work is the consideration of the capture efficiency in the diffusion controlled phase of carbonation. It is demonstrated that increasing the residence time by a few minutes in the carbonator yields a significant improvement of the capture efficiency. Model predictions are shown to agree with experimental results retrieved from pilot-scale tests. The new model allows a more accurate evaluation and prediction of carbonator's performance over a wider range of residence times. The results obtained may be relevant for the optimization of CaL operation parameters to be integrated in real power plants.
\end{abstract}

Keywords: $\mathrm{CO}_{2}$ capture, Ca-looping, limestone calcination, diffusion phase, calcium looping, carbon dioxide capture.

\section{Introduction}

Taking into account the current energy system and its expected evolution, capture and permanent geological storage of $\mathrm{CO}_{2}$ from fossil fuel power plants is considered as a necessary technology to be developed at commercial scale in the short term for mitigation of global warming. The IPCC [1] has evaluated existing and emerging technologies of $\mathrm{CO}_{2}$ capture and storage (CCS) and concludes that, in most scenarios, CCS should contribute by a 
$15-55 \%$ to the cumulative global mitigation effort until 2100. Amongst the $\mathrm{CO}_{2}$ capture technologies potentially foreseeable for commercial development, the Ca-Looping (CaL) process is highlighted as one with good prospects for post-combustion capture, mainly due to the possibility of being implemented in already existing power plants and the minor penalty on plant performance as compared to other capture technologies such as conventional 5 amine-based capture systems [2,3]. A further advantage of the CaL technology is the low price, wide availability and harmlessness towards the environment of the sorbent precursor raw material, namely natural limestone $[2,4,5]$

The CaL technology for $\mathrm{CO}_{2}$ post-combustion capture is based on the reversible chemical reaction of carbonationcalcination of $\mathrm{CaO}$. The basic cycle involves $\mathrm{CO}_{2}$ capture from the flue gas stream of a power plant using lime (CaO) derived from calcination of natural limestone:

$$
\mathrm{CaO}(s)+\mathrm{CO}_{2} \rightleftarrows \mathrm{CaCO}_{3(s)} \quad \Delta H_{r}^{0}=-178 \frac{\mathrm{kJ}}{\mathrm{mol}}
$$

Flue gases from coal-fired power plants generally contain a mole fraction of $\mathrm{CO}_{2}$ in the range of $10-15 \%[6,7]$, whereas typical residence times in the carbonator reactor would be on the order of minutes. Taking into account these constraints, optimum carbonation temperatures are around $650^{\circ} \mathrm{C}$ for a quick enough reaction kinetics and low value of the equilibrium $\mathrm{CO}_{2}$ concentration in order to achieve significant efficiencies of $\mathrm{CO}_{2}$ capture (around 80-90\%) [8]. Efficient gas-solid contact and heat/mass transfer would be ensured by the use of circulating fluidizedbed reactors (CBF). CFBs are typically operated at atmospheric pressure under the fast fluidization regime, with gas velocities of the order of $5-10 \mathrm{~m} / \mathrm{s}[9,10]$. The partially carbonated particles are driven into a second fluidized bed reactor (calciner), where $\mathrm{CaO}$ is regenerated by calcination under high temperatures and necessarily high $\mathrm{CO}_{2}$ concentration [11-14].

Once $\mathrm{CO}_{2}$ is captured in the carbonator and heat from the exothermic reaction is recovered, the flue gas almost free of $\mathrm{CO}_{2}$ is released into the atmosphere. After a residence time in the carbonator of a few minutes, the carbonated solids are circulated into the calciner. Coal is burned into the calciner reactor using pure $\mathrm{O}_{2}$ (oxycombustion) to increase the temperature up to the value required for the endothermic calcination reaction to occur fast and avoid $\mathrm{CO}_{2}$ dilution at the same time. Thus, $\mathrm{CO}_{2}$ is retrieved from the calciner for compression, transport and geological storage or other uses. The regenerated sorbent produced in the calciner is returned to the carbonator for a new cycle. 
In order to predict the efficiency of $\mathrm{CO}_{2}$ capture by integrating the $\mathrm{CaL}$ technology on existing power plants, a number of models have being proposed in the literature [15-18]. Besides, several pilot-medium scale plants (up to 1.7 MWth) demonstrate a high $\mathrm{CO}_{2}$ capture efficiency, which raises hopes on a successful scale-up of the technology $\underline{[13,14,19-21]}$. Interestingly, the CaL technology is also suitable to be integrated with biomass combustion as shown

5 in a pilot-scale plant $\left(300 \mathrm{~kW}_{\text {th }}\right)$, which would allow producing power with negative $\mathrm{CO}_{2}$ emissions [20].

The multicyclic calcination/carbonation behavior of $\mathrm{CaO}$ used in current carbonator models has been inferred from thermogravimetric analysis (TGA) results in which calcination is usually carried out under low $\mathrm{CO}_{2}$ partial pressure mainly due to technical difficulties. Under these conditions, most of the carbonation reaction in short residence times occurs on the surface of the $\mathrm{CaO}$ particles through a kinetically controlled fast phase whereas the subsequent solid-state diffusion controlled phase is comparatively negligible as will be seen in detail below. The present manuscript proposes a new carbonator model that does consider the relevant effect of realistic calcination conditions, necessarily involving calcination under high $\mathrm{CO}_{2}$ pressure, on the multicyclic $\mathrm{CaO}$ conversion behavior. In order to stress the relevant role of calcination conditions on the sorbent performance, the next section is devoted to briefly review recent TGA results that will be employed in the formulation of the new carbonator model. We

follow up with the development of the carbonator model. Finally, capture efficiency results from the new model are compared with predictions by models reported in the literature and pilot-scale results.

\section{A brief review on the role of calcination conditions on the multicyclic $\mathrm{CO}_{2}$ capture behavior of limestone}

Results of TGA tests show that the multicyclic $\mathrm{CO}_{2}$ capture capacity of limestone derived $\mathrm{CaO}$ is strongly influenced 20 by the conditions under which calcination is performed [22-24]. The most feasible method to generate the heat required in the calciner while at the same time avoiding $\mathrm{CO}_{2}$ dilution is to burn coal by oxy-combustion $[4,11-14]$. Thus, calcination is carried out in an environment containing between $70 \%$ and $90 \%$ vol. concentration of $\mathrm{CO}_{2}$ at atmospheric pressure $[11,23,25-27]$. Calcination kinetics becomes extremely slow under high $\mathrm{CO}_{2}$ partial pressures nearby equilibrium ( $\left.\mathrm{T} \approx 870-900^{\circ} \mathrm{C}\right)$ [22]. This makes necessary to increase the temperature over $930^{\circ} \mathrm{C}$ to increase the $\mathrm{CO}_{2}$ partial equilibrium pressure well above the $\mathrm{CO}_{2}$ partial pressure in the calciner and yield sufficiently fast reaction kinetics in short residence times $[14,21,28]$.

\subsection{Sorbent deactivation}


The combination of high temperature and high concentration of $\mathrm{CO}_{2}$ during calcination enhances the progressive deactivation of the sorbent as the number of cycles builds up due to enhanced sintering [29-32]. Enhanced sintering of $\mathrm{CaO}$ has a strongly negative effect on the active surface of the solids available for the gas-solid reaction in the kinetically driven fast phase. Grasa et al. [33] proposed to fit the observed evolution of CaO conversion $X_{N}$

5 (ratio of mass of $\mathrm{CaO}$ converted to $\mathrm{CaCO}_{3}$ to mass of $\mathrm{CaO}$ initial) with the number of cycles by means of the equation (2):

$$
X_{N}=\frac{1}{\frac{1}{1-X_{r}}+\kappa N}+X_{r}
$$

where $\kappa=0,52$ and $X_{r}=0,075$ are the deactivation constant and the residual conversion, respectively. This equation is however based on results from multicyclic calcination/carbonation TGA tests in which the sorbent is regenerated

by calcination under low $\mathrm{CO}_{2}$ partial pressure. Thus, conversion after $1^{\text {st }}$ calcination $\left(\mathrm{X}_{1}\right)$ is rather high (around 0.7 ). This high value of conversion is due to the relatively high porosity of the $\mathrm{CaO}$ particles derived by short-time calcination under low $\mathrm{CO}_{2}$ partial pressure. Despite that Equation (2) cannot reflect the effect of calcination under high $\mathrm{CO}_{2}$ pressure as would be the case in the $\mathrm{CaL}$ technology, it has been routinely used in theoretical studies as representative of the sorbent behavior in order to model the carbonator reactor [15-18].

In more recent TGA studies [34,35], a modified equation was proposed using data obtained from multicyclic calcination/carbonation tests under more realistic calcination conditions involving high $\mathrm{CO}_{2}$ partial pressure $(70 \%$ $\mathrm{v} / \mathrm{v} \mathrm{CO} 2,30 \%$ air) at temperatures of $950^{\circ} \mathrm{C}$ as well as fast transitions between the calcination and carbonation stages. The modified equation proposed is:

$$
\frac{X_{N}}{X_{1}}=\frac{X_{r}}{X_{1}}+\left(\frac{1}{\kappa(N-1)+\left(1-\frac{X_{r}}{X_{1}}\right)^{-1}}\right)
$$

20 where $\kappa=0,776$ and $X_{r}=0,077$ and $X_{1}=0,48$ is $\mathrm{CaO}$ conversion after $1^{\text {st }}$ calcination. Carbonation/calcination conditions in these tests where $650 \circ \mathrm{C} / 5 \mathrm{~min}$ for carbonation under $15 \% \mathrm{CO}_{2}$ and $950 \circ \mathrm{C} / 5 \mathrm{~min}$ for calcination under $70 \% \mathrm{CO}_{2}$.

Equation (3) looks similar to equation (2), but with the main difference that it takes into accounts the smaller value of conversion in the first cycle after calcination under high $\mathrm{CO}_{2}$ partial pressure. Besides, the deactivation constant 25 is higher as compared to that derived from tests carried out calcining under low $\mathrm{CO}_{2}$ partial pressure. In the real 
process, a makeup flow of fresh limestone must be continuously fed into the calciner in order to compensate for sorbent deactivation. Limestone is therefore first calcined in the stationary state under high $\mathrm{CO}_{2}$ partial pressure at the same conditions that the partially carbonated solids are calcined for $\mathrm{CaO}$ regeneration. Thus, the use of equation (3) for modelling the carbonator reactor might help simulating more realistic CaL conditions.

\subsection{Fast and slow carbonation stages}

Two well differentiated stages can be observed during carbonation of $\mathrm{CaO}$ solid particles [30,36-38]. The first stage takes place on the free surface of the solid through the nucleation and growth of $\mathrm{CaCO}_{3}$ and is governed by the kinetics of the reaction between $\mathrm{CaO}$ and $\mathrm{CO}_{2}$. The end of the fast stage takes place when a $40-60 \mathrm{~nm}$ thickness

product layer is formed, which makes inaccessible a large fraction of $\mathrm{CaO}$ in the interior of the particles for fast kinetically controlled carbonation [39]. Once the $\mathrm{CaO}$ free surface directly available for fast carbonation has been covered the reaction continues in a second stage which is controlled by the solid-state diffusion of $\mathrm{CO}_{3}{ }^{2-}$ and $\mathrm{O}^{2-}$ ions through the product layer, which is a much slower process $[40,41]$.

TGA results show that the solid-state diffusion controlled carbonation is greatly enhanced when $\mathrm{CaO}$ is regenerated under high $\mathrm{CO}_{2}$ partial pressure as compared to calcination under low $\mathrm{CO}_{2}$ concentration $[26,42,43]$. Figure 1 shows the time evolution of sorbent weight during the first calcination/carbonation cycles of two TGA tests in which calcination was carried out either under high $\mathrm{CO}_{2}$ partial pressure or air. The results show that carbonation in the fast initial phase is extraordinarily hindered when the sorbent is regenerated under high $\mathrm{CO}_{2}$ concentration. Even though the reaction rate is similar for the two tests, the maximum carbonation conversion in the fast phase is 20 significantly hampered for the sorbent regenerated under high $\mathrm{CO}_{2}$ partial pressure essentially due to severe sintering and drastic reduction of the surface area [22]. On the other hand, carbonation in the diffusion controlled phase is notably enhanced when calcination is carried out under high $\mathrm{CO}_{2}$ concentration especially in the first cycles. 

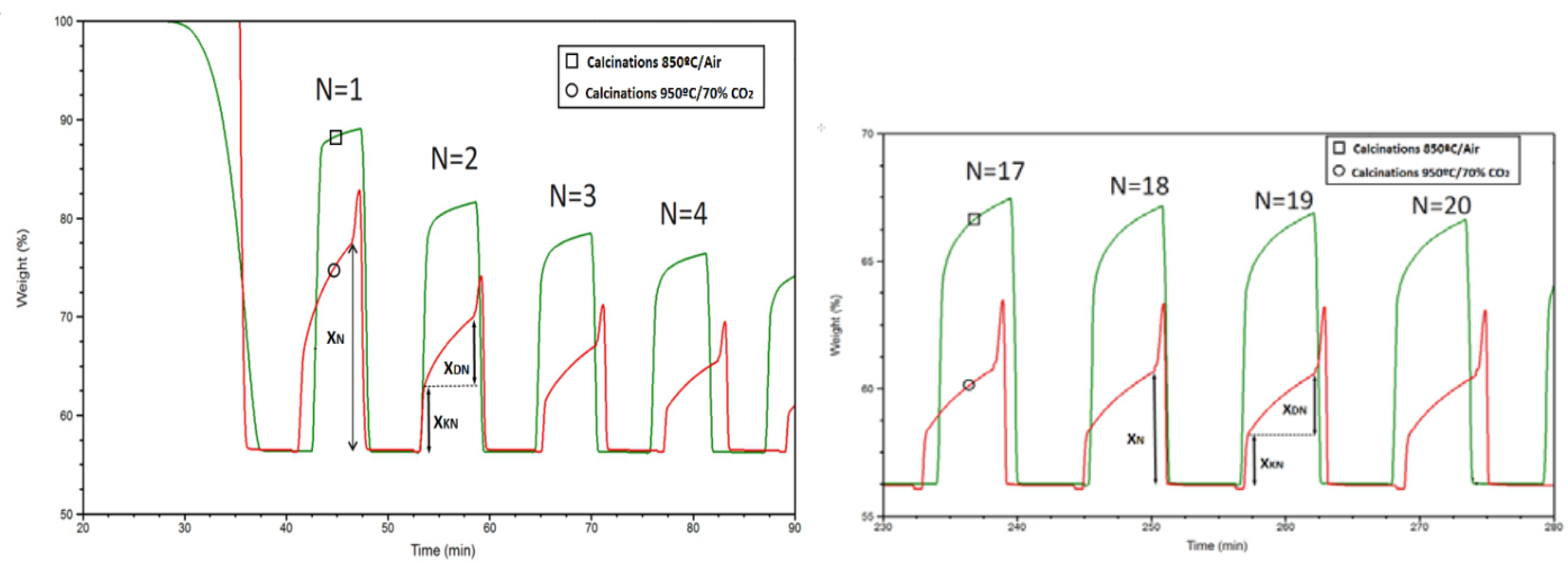

Figure 1: Time evolution of sorbent weight\% during precalcination and subsequent carbonation/calcination cycles. Carbonation at 650 ㅇ C for $5 \mathrm{~min}\left(15 \% \mathrm{CO}_{2} / 85 \%\right.$ air vol/vol). Different calcination conditions are indicated. Reproduced from data reported in [35].

A close examination of TGA test results reported in the literature for $\mathrm{CaO}$ derived from other precursors such as steel slag (Figure 2a) and results obtained from pilot scale tests (Figure $2 \mathrm{~b}$ ) reveals also that the relatively slower solid-state diffusion controlled phase contributes substantially to carbonation for residence times of a few minutes.
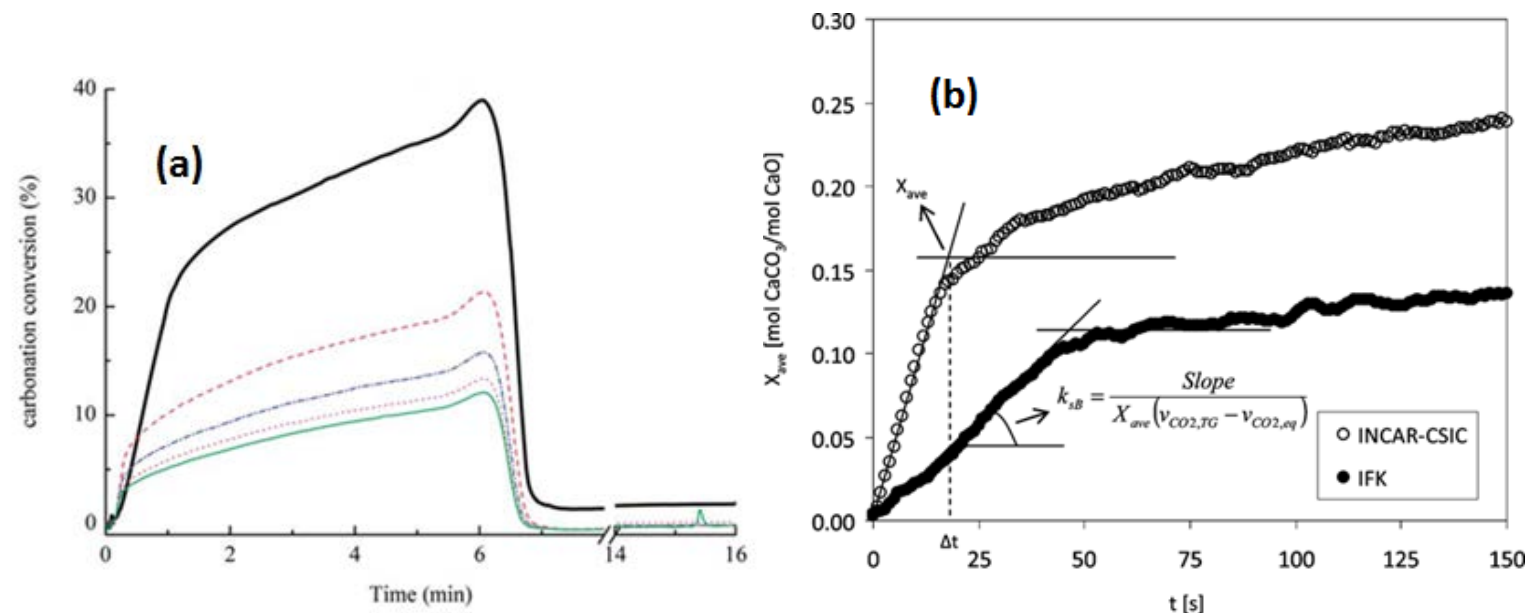

Figure 2: (a) Time evolution conversion of steel slag during the first, 5th, 10th, 15th, and 20th cycles (reproduced from [48] with permission). (b) Average $\mathrm{CO}_{2}$ carrying capacity $\left(\mathrm{X}_{\text {ave }}\right)$ vs. time and reaction constant $\left(\mathrm{k}_{\mathrm{sB}}\right)$, derivation for sample removed from the CFB carbonator during operation in pilot-scale test (reproduced from [28] with permission).

15 Figure 3 shows the multicyclic evolution of $\mathrm{CaO}$ conversion in the kinetically controlled $\left(\mathrm{X}_{\mathrm{NK}}\right)$ and diffusion controlled $\left(\mathrm{X}_{\mathrm{ND}}\right)$ carbonation stages derived from TGA tests reported in [35] in which calcination was carried out under high $\mathrm{CO}_{2}$ partial pressure. Both $\mathrm{X}_{\mathrm{NK}}$ and $\mathrm{X}_{\mathrm{ND}}$ can be pretty well fitted by equation (3) using the parameters given in table 1. 
Table 1: Fitting parameters for sorbent deactivation curves of conversion in the kinetic and diffusion controlled stages (Fig. 3).

\begin{tabular}{|c|c|c|}
\hline Carbonation stage: & Kinetic & Diffusion \\
\hline Time: & 0,3 min & 5 min \\
\hline Deactivation constant: & $\kappa_{\mathrm{K}}=0,676$ & $\mathrm{\kappa}_{\mathrm{D}}=0,871$ \\
\hline Residual conversion: & $\mathrm{Xr}_{\mathrm{K}}=0,0296$ & $\mathrm{Xr}_{\mathrm{D}}=0,0408$ \\
\hline $\mathbf{1}^{\text {st }}$ cycle conversion: & $\mathrm{X}_{1, \mathrm{~K}}=0,0218$ & $\mathrm{X}_{1, \mathrm{D}}=0,263$ \\
\hline
\end{tabular}

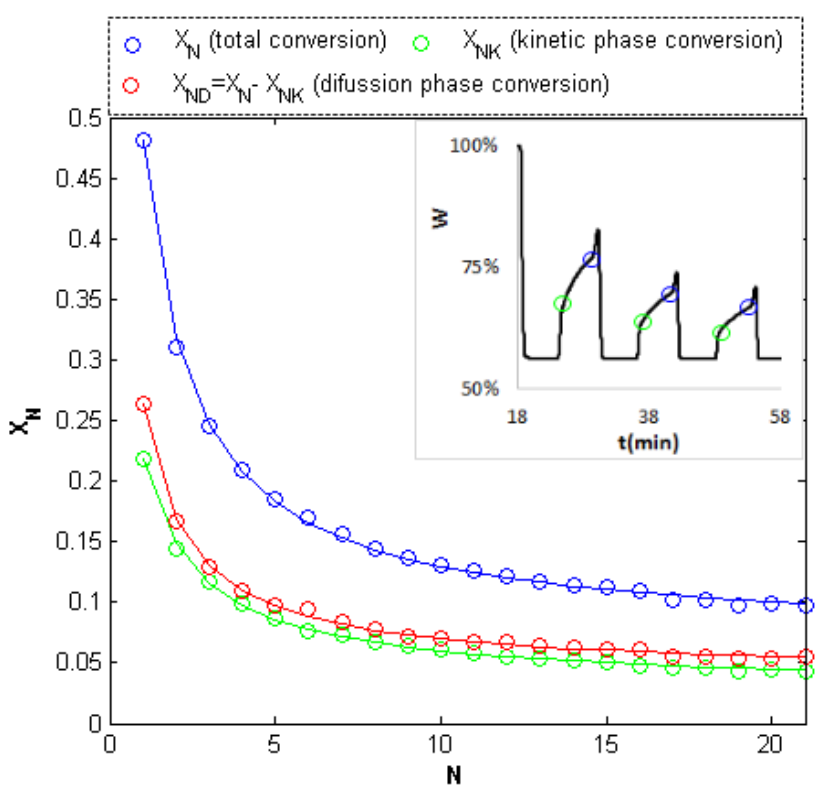

Figure 3: $\mathrm{CaO}$ conversion in the kinetically controlled carbonation stage $\left(\mathrm{X}_{\mathrm{NK}}\right)$ and in the diffusion controlled stage ( $\left.\mathrm{X}_{\mathrm{ND}}\right)$ as a function of the cycle number. Pre-calcination and calcinations conditions: $\mathrm{CO}_{2}$ vol\% $=70 \%, \mathrm{t}=5 \mathrm{~min}, \mathrm{~T}=950$ \% $\mathrm{C}$. Carbonation conditions: $\mathrm{CO}_{2}$ vol\% $=15 \%, \mathrm{t}=5 \mathrm{~min}, \mathrm{~T}=650 \circ \mathrm{C}$. The inset shows the time evolution of sorbent wt $\%$ in the first $3 \mathrm{cycles}$. Obtained from data originally reported in [42].

As can be seen in Figure 3, the contribution of the diffusion controlled phase to $\mathrm{CaO}$ conversion is quite relevant being of the same order than $\mathrm{CaO}$ conversion in the kinetically controlled phase for 5 min overall carbonation periods. Moreover, an increase of the carbonation phase above 5 min would lead to higher conversion in the diffusive phase since carbonation in this stage grows roughly linearly with time until carbonation is completed [42].

Thus, it seems clear that a carbonator model should consider carbonation in the diffusion stage in order to predict realistic values of efficiency and to draw useful conclusions on the optimum operating parameters in a commercial plant. This is the main goal of the present manuscript. 


\section{Carbonator model approach}

\subsection{Kinetic model}

As mentioned in the introduction, in order to predict the $\mathrm{CO}_{2}$ capture efficiency of the CaL technology, many authors [15-18] propose to simplify the $\mathrm{CaO}$ conversion behavior by assuming that it reaches a maximum value, $\mathrm{X}_{\mathrm{N}}$, at a 5 constant rate (proportional to the free surface available of $\mathrm{CaO}$ and the thickness of the $\mathrm{CaCO}_{3}$ layer formed) in a time $t_{\text {lim, }}$ after which the reaction rate drops to zero (solid lines in Fig. 4a). This simplifying assumption would be reasonable if calcination was performed under low $\mathrm{CO}_{2}$ partial pressure. However, as pointed out above, the diffusive carbonation phase plays a relevant role for calcination under high $\mathrm{CO}_{2}$ partial pressure whereas the kinetically controlled carbonation stage is severely hampered. Using the multicyclic TGA results reported in $[34,35,42]$, we develop below a modified carbonator model built upon the model proposed by Alonso et al. [18]. The main novelty of our model is that carbonation in the diffusion controlled phase will be considered to predict the carbonation efficiency.

Figure 4 (a) shows experimental results from TGA tests in which calcinations were carried out under low $\mathrm{CO}_{2}$ partial pressure. The solid lines are the kinetic curves assumed in the carbonator model described in [18]. As can be seen, the diffusion controlled stage is negligible in the first cycles but as the number of cycles is increased the diffusive conversion becomes more important (see results for cycle $\mathrm{N}=20$ in Figure 4(a)). As seen in Figure 4 (a) the time for the kinetic stage $\left(t_{k}\right)$ decreases with the number of cycles as conversion in the diffusive phase is enhanced, which is however dismissed in the theoretical model (solid lines). Figure 4(b) illustrates the kinetic curves proposed in our work as representative of the experimental curves reported in [42] in which calcinations were carried out under high $\mathrm{CO}_{2}$ partial pressure. It is assumed that the time evolution of $\mathrm{CaO}$ conversion can be approximated by two lines of constant slope, one corresponding to the kinetically controlled carbonation stage and another for the diffusive carbonation stage. In this way, the new kinetic model has into account the relevant role of the diffusion controlled phase. According to experimental measurements, conversion would be increased roughly linearly with time in the diffusion controlled stage against the widely accepted conception that once the fast kinetically controlled phase is completed, additional carbonation by solid-state diffusion is negligible. Thus, it may be anticipated that an important parameter influencing the carbonation efficiency would be the residence time of the solids in the carbonator. 

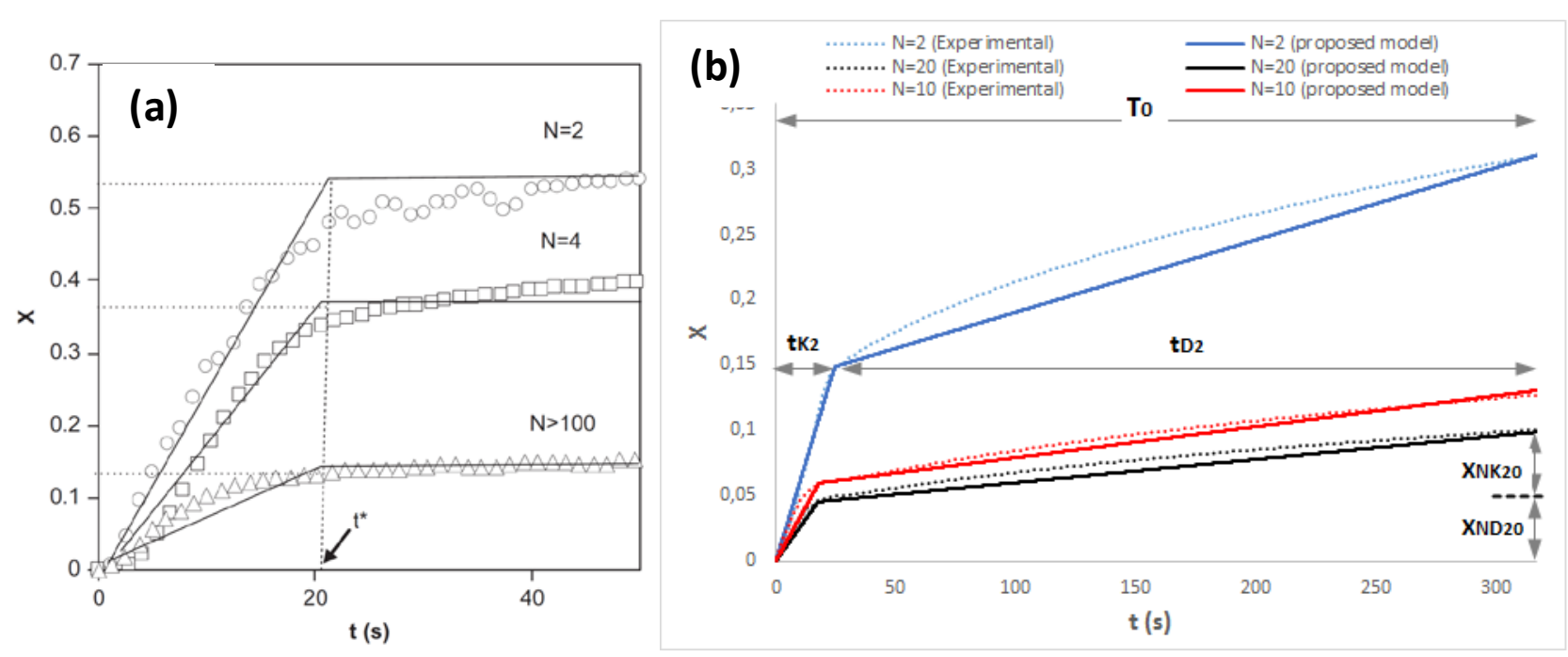

5 Figure 4: $\mathrm{CaO}$ conversion as a function of time for different cycles showing in (a) the theoretical approximation for the kinetic model (solid lines) to describe the progress of the carbonation reaction with time (reproduced from [18] with permission). Data points are experimental results from TGA tests in which calcination was carried under low $\mathrm{CO}_{2}$ concentration. In (b) the kinetic model curves proposed in the present article (solid lines) are shown superposed to experimental data from TGA tests reported in [49] in which calcination was carried out under high $\mathrm{CO}_{2}$ concentration (dotted lines). Note the different scales in (a) an (b) for the $\mathrm{CaO}$ conversion degree.

According to the kinetic model proposed in this work (solid lines in Fig 4(b)), the reaction rate can be expressed as a function of residence time in the carbonator by the following expression:

$$
r_{N_{-} i}=\left\{\begin{array}{c}
r_{N_{K}}=\frac{X_{N K}}{t_{K}} \quad \text { for } t \leq t_{K} \\
r_{N_{D}}=\frac{X_{N D}}{T_{0}-t_{k}} \text { for } t_{K}<t \leq t_{\max }
\end{array}\right\}
$$

where $r_{N_{i}}$ is the reaction rate in the $i$-phase (either kinetic or diffusion), $t_{k}$ is the time the kinetic phase takes, $t_{\max }$ is the residence time of the particles in the carbonator, and $X_{N D} /\left(T_{0}-t_{K}\right)$ is the rate of diffusive conversion that will be derived from experimental results.

Using experimental data reported in [42], the reaction rates in the kinetic phase $\left(r_{N k}\right)$ and diffusive phase $\left(r_{N D}\right)$ can be adjusted as a function of the number of cycles $N$ using Eq. (3) as shown in Figure 5. 


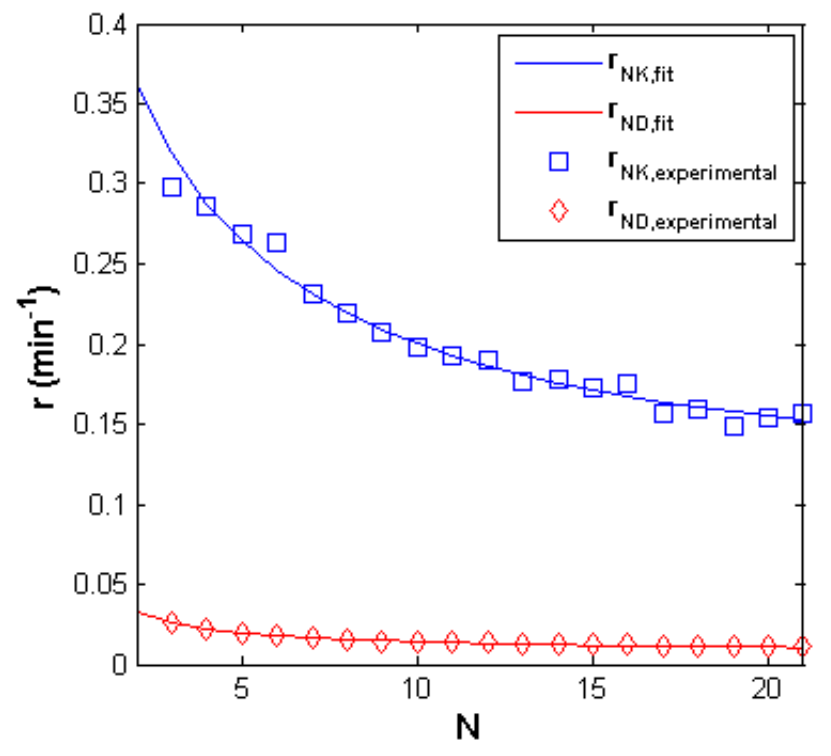

Figure 5: Rate of kinetic and diffusive carbonation ( $r_{N D}, r_{N K}$ respectively) as a function of number of cycles from experimental data reported in [42] obtained by means of TGA tests. The solid lines are best fit curves using Eq. 3 yielding residual values of the kinetic and diffusion rates of 0.096 and 0.0082 , respectively and deactivation constants of the kinetic and diffusion rates of 0.315 and 0.917 , respectively

According to Bhatia et al. [38], the rate of $\mathrm{CaO}$ conversion in the kinetically controlled fast phase at atmospheric pressure, can be expressed by a first-order kinetic law:

$$
\frac{d X}{d t}=r_{N K}=k_{S} S_{N}(1-X)^{\frac{2}{3}}\left(C_{C O 2}-C_{C O 2} e q\right)
$$

where $C_{\mathrm{CO} 2}$ and $C_{\mathrm{CO} e q}$ are the actual and equilibrium $\mathrm{CO}_{2}$ concentrations, respectively, and $k_{s}$ is the kinetic constant. $\mathrm{S}_{\mathrm{N}}$ is the $\mathrm{CaO}$ specific area available for reaction after $N$ cycles, which is proportional to the particle conversion degree. As can be seen in Figure 5, the reaction rate in the kinetic phase $\left(r_{N k}\right)$ decays with the number of cycles due to the effect of sintering that leads to a decrease of the available surface $\left.S_{N}\right)$.

By integrating Eq. (5) and fitting it to the experimental data reported in [42], we obtain a value of the kinetic constant $k_{s}=6,7 \times 10^{-10} \mathrm{~m}^{4} /(\mathrm{mol} \cdot \mathrm{s})$, which is similar to the value reported by other authors $[38,44]$ also for natural limestone but under different operating conditions as regards calcination. This suggests that the kinetics of carbonation in the fast phase is essentially determined by the $\mathrm{CaO}$ surface area and does not depend on the calcination conditions. The essential effect of calcination under $\mathrm{CO}_{2}$ would be thus to enhance sintering, which greatly reduces the available surface area for carbonation and therefore the duration of the kinetic phase.

The rate of conversion in the diffusion controlled phasecan be expressed using an effective diffusion constant $D_{\text {eff }}$ [40]: 


$$
\frac{d X}{d t}=r_{N D}=\frac{D_{e f f}\left(C_{C O 2}-C_{C O 2_{e q}}\right)}{\frac{2}{3}(1-X)^{-\frac{1}{3}}-\frac{2}{3}(Z+(1-Z)(1-X)]^{-\frac{1}{3}}}
$$

where $\mathrm{Z}$ is the ratio of the molar volume of $\mathrm{CaCO}_{3}$ and $\mathrm{CaO}$. Equation 6 can be adjusted to the experimental data (Fig. 5) to obtain a value for the diffusion constant. As seen from the experimental results (Fig. 5) the rate of carbonation in the diffusive stage remains approximately constant with the number of cycles. In [42], some of the TGA tests presented were made by prolonging the carbonation stage up to 30 minutes showing that the rate of carbonation in the diffusion controlled phase did not change appreciably over this time interval. Thus, we may neglect as a first approximation the dependence of the diffusive reaction rate on conversion and use the simplified expression:

$$
r_{N D} \approx D^{*}{ }_{e f f}\left(C_{C O 2}-C_{C O 2}{ }_{e q}\right)
$$

10 where $D^{*}{ }_{e f f}$ is an effective diffusion constant. By using $r_{N D} \approx 0.01 \mathrm{~min}^{-1}(\mathrm{Fig} .5)$ a value of $D^{*}{ }_{\text {eff }}=6,5 \times 10^{-5} \mathrm{~m}^{3} /(\mathrm{mol}$ $\cdot s)$ is obtained.

\subsection{Capture model}

In figure 6 we show the global scheme for the CaL system with the definition of main parameters used for defining and evaluating $\mathrm{CO}_{2}$ capture.

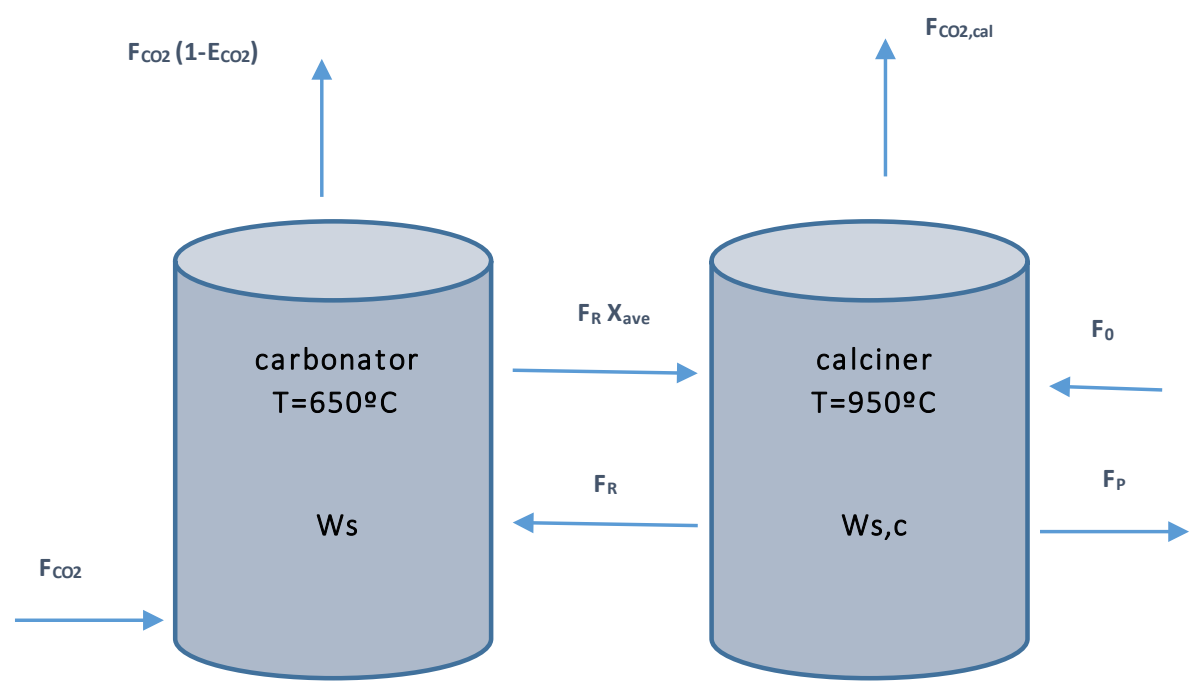

Figure 6: Scheme of the CaL post-combustion capture model

The average conversion of the $\mathrm{CaO}$ particles present in the reactor $\left(X_{\text {ave }}\right)$ is given by the sum of conversion in the kinetic fast phase $\left(X_{\text {ave, },}\right)$ plus conversion in the diffusive phase $\left(X_{\text {ave }, D}\right)$ : 


$$
X_{a v e}=X_{a v e, K}+X_{a v e, D}
$$

For a given continuous supply of fresh limestone into the calciner and a given solids purge, the fraction of particles subjected to a given number of cycles $N$ is given by [30]:

$$
r_{N}=\frac{F_{0} F_{R}^{N-1}}{\left(F_{0}+F_{R}\right)^{N}}
$$

5 The average maximum conversion $\left(X_{m a z, a v e}\right)$ can be calculated as the weighted sum of conversions after $N$ cycles:

$$
\begin{gathered}
X_{\text {max }, \text { ave }}=\sum_{N=1}^{N=\infty} r_{N} X_{N} \text { (10) } \\
X_{\text {max }, \text { ave }}=X_{\text {max }, \text { ave }, K}+X_{\text {max }, \text { ave }, D}=\sum_{N=1}^{N=\infty} r_{N} X_{N K}+\sum_{N=1}^{N=\infty} r_{N} X_{N D}
\end{gathered}
$$

The average reaction rate depends on the phase the particles are reacting as:

$$
r_{\text {ave } i}=\left\{\begin{array}{c}
r_{a v e_{,}}=\frac{X_{\text {max }, a v e, K}}{t_{K}} \text { si } t \leq t_{K} \\
r_{\text {ave }, D}=\frac{X_{\text {max }, \text { ave }, D}}{T_{0}-t_{k}} \text { si } t_{K}<t \leq \tau
\end{array}\right\}
$$

where $\tau$ is the average residence time of the particles in the carbonator:

$$
\tau=\frac{N_{C a}}{F_{R}}=\frac{W_{s}}{56 F_{R}}
$$

The average conversion of the particles leaving the carbonator can be obtained from the sum of the average particle conversion reacting in the fast carbonation phase $\left(X_{a v e, K}\right)$ and the average particle conversion reacting in the diffusive phase $\left(X_{\text {ave }, D}\right)$ :

$$
\begin{gathered}
X_{\text {ave }}=X_{\text {ave }, K}+X_{a v e, D}=\left.f_{a} X\right|_{\leq t_{K}}+\left.\left(1-f_{a}\right) X\right|_{>t_{K}} \\
\left.X\right|_{\leq t_{K}}=\frac{\int_{0}^{t_{K}} r_{a v e, K} t\left(\frac{1}{\tau}\right) e^{-\frac{t}{\tau}} d t}{1-e^{-\frac{t_{K}}{\tau}}} \\
\left.X\right|_{>t_{K}}=X_{\text {max }, a v e, K}+\frac{\int_{t_{K}}^{\tau} r_{a v e, D} t\left(\frac{1}{\tau}\right) e^{-\frac{t}{\tau}} d t}{1-e^{-\frac{t_{K}}{\tau}}}
\end{gathered}
$$

where $t_{D}=\tau-t_{K}$ and $f_{a}$ is the fraction of particles reacting in the kinetic phase, which is given by [18]

$$
f_{a}=\left(1-e^{-\frac{t_{K}}{\tau}}\right)
$$


The average surface area for reaction in the kinetic phase can be expressed by [44]:

$$
S_{a v e_{K}}=\frac{V_{M_{C a C O}} X_{\text {max }, a v e, K}}{M_{C a O} h} \rho_{C a O}
$$

Since conversion is typically low except for the first cycles, Eq. (5) can be simplified by dismissing the dependence on conversion as done in [18]. Thus, it is possible to express the average reaction rate in each carbonation phase 5 as:

$$
\begin{gathered}
r_{\text {ave }_{K}}=k_{S} S_{\text {ave }_{K}}\left(C_{\mathrm{CO}^{2}}-C_{\mathrm{CO}_{e q}}\right) \\
r_{\text {ave }_{D}}=D^{*}{ }_{\text {eff }}\left(C_{\mathrm{CO} 2}-C_{\mathrm{CO}_{e q}}\right)
\end{gathered}
$$

The capture efficiency in the carbonator $E_{\mathrm{CO} 2}$ can be calculated as [18]:

$$
\begin{aligned}
E_{C O 2} & =\frac{F_{R}}{F_{C O 2}} X_{\text {ave }} \\
E_{C O 2, K} & =\frac{F_{R}}{F_{C O 2}} X_{\text {ave }, K} \\
E_{C O 2, D} & =\frac{F_{R}}{F_{C O 2}} X_{\text {ave } D}
\end{aligned}
$$

where the capture efficiency in the fast phase $\left(E_{C O 2, K}\right)$ and the diffusive phase $\left(E_{C O 2, D}\right)$ have been considered as separate contributions in order to evaluate their relative weight.

Assuming that the gas passes in plug flow through a bed of perfectly mixed solids, the carbon mass balance in the

gas phase in a differential element of the carbonator reactor can be written as:

$$
F_{C O 2} \frac{d E_{C O_{2}}}{d z}=A \frac{\rho_{C a O}}{V_{M_{C a O}}}\left(f_{a} r_{a v e_{K}}+\left(1-f_{a}\right) r_{a v e_{D}}\right)
$$

Integrating Eq. (24) along the carbonation reactor, it results

$$
\psi=\left[-\frac{f_{0}}{f_{0} f_{e}-f_{0}} E_{C O_{2}}+\frac{f_{0}\left(f_{0}-1\right)}{\left(f_{0} f_{e}-f_{0}\right)^{2}} \ln \left(\frac{\left(f_{0}-f_{e}\right)+\left(f_{0} f_{e}-f_{0}\right) E_{C O_{2}}}{f_{0}-f_{e}}\right)\right]
$$

where,

$$
z=\frac{F_{C O 2} \cdot M_{C a O}}{W_{s} \cdot \rho_{g} \cdot\left(S_{a v e_{K}} \cdot f_{a} \cdot k_{s}+D_{e f f_{s i m}} \cdot\left(1-f_{a}\right)\right.} \psi
$$

and $f_{e}$ and $f_{0}$ are the equilibrium and inlet molar fraction of $\mathrm{CO}_{2}$, respectively. 


\section{Model results}

A series of parametric calculations have been carried out to determine the $\mathrm{CO}_{2}$ capture efficiency of the carbonator under different operating conditions. The calculations are made for a typical coal combustion power plant using a value of 0.15 for the volumetric fraction of $\mathrm{CO}_{2}$ in the flue gas entering the carbonator and a flow rate $F_{\mathrm{CO} 2}=0.1 \mathrm{~kg}$

$5 \quad \mathrm{CO}_{2} / \mathrm{s}$ as typical values [18].

In the first run we will use as key input parameters the solid inventory in the carbonator reactor $\left(W_{s}\right)$, the flow rate of fresh limestone makeup $\left(F_{0}\right)$ fed into the calciner and the flow rate of solids entering the carbonator coming from the calciner $\left(F_{R}\right)$. As for the rest of parameters, the same representativevalues employed in previous works [18] will be used (Table 2). Figures 7 and 8 show the calculated capture efficiency as function of the total solid inventory in the reactor $W$ (normalized per $\mathrm{MW}_{\text {th }}$ ) for different values of $F_{R}$ and $F_{0}$.

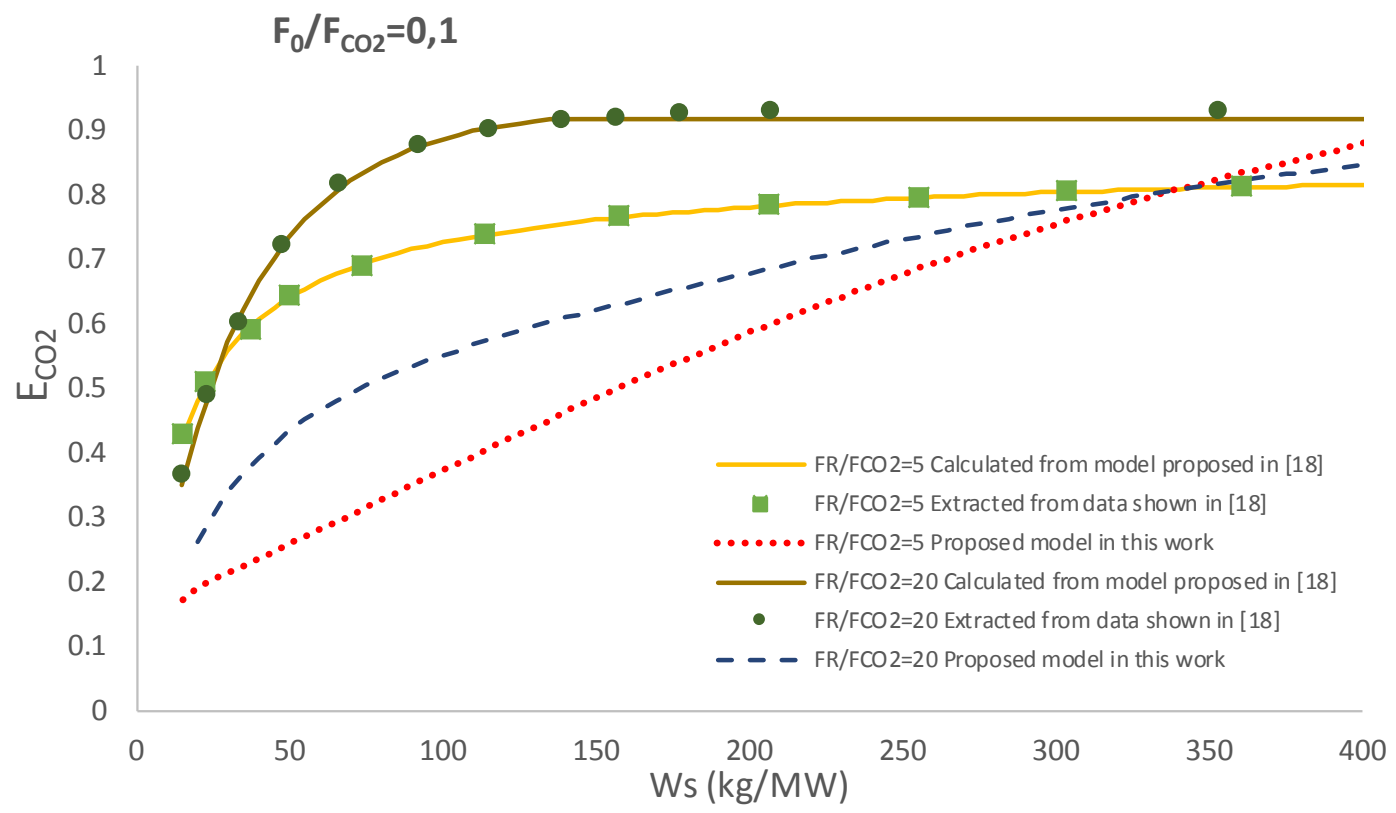

Figure 7: Capture efficiency calculated as a function of the solids inventory in the carbonator for different $F_{R} / F_{C O 2}$ ratios according to the model presented in [18] and the new model proposed in this work. 


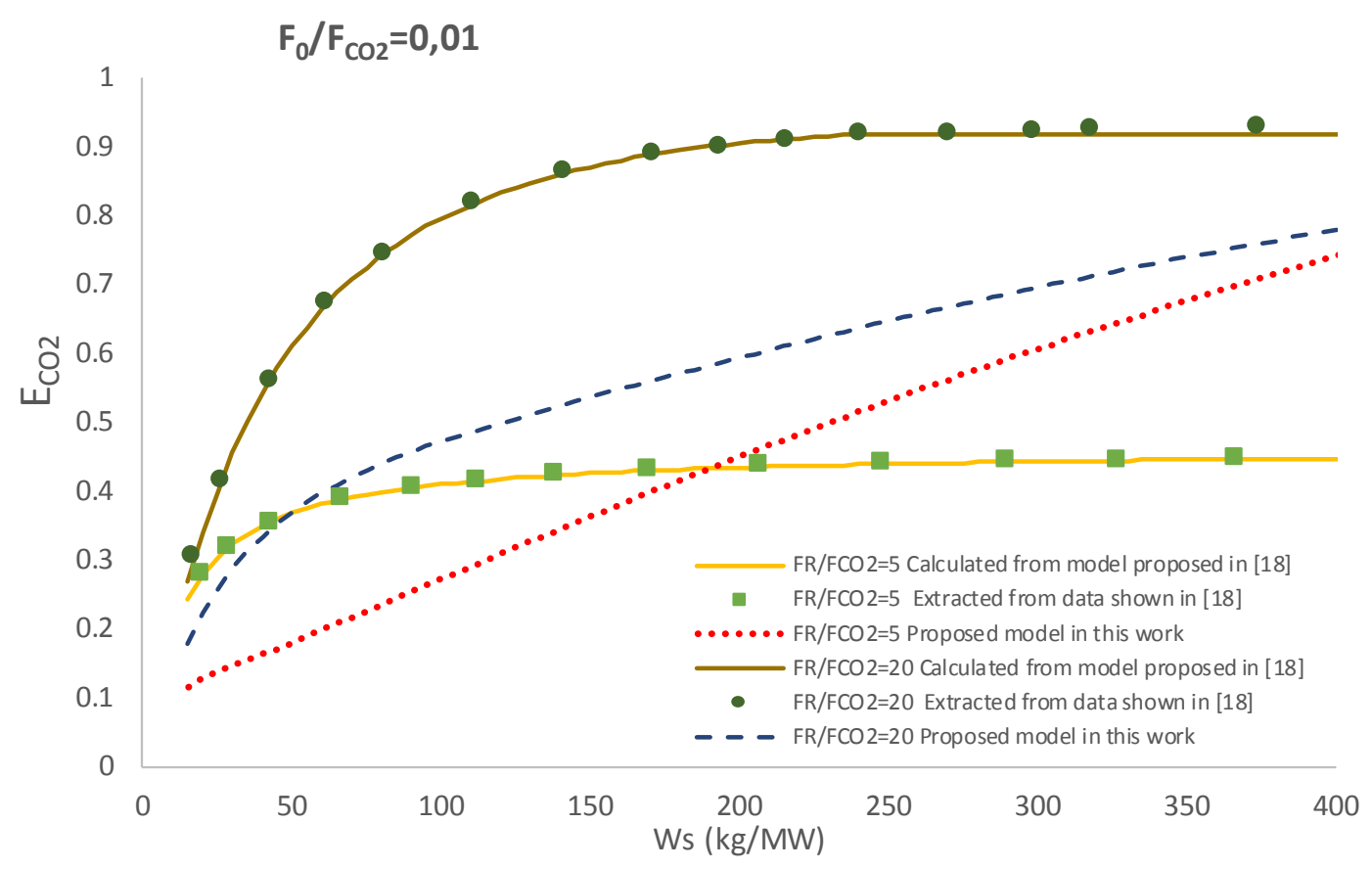

Figure 8: Carbonation efficiency as a function of the solids inventory in the carbonator at different $\mathrm{F}_{\mathrm{R}} / \mathrm{F}_{\mathrm{CO} 2}$ ratios according to the model presented in [18] and the new model proposed in this work.

Table 2: Values of the parameters used for the calculation of capture efficiency.

\begin{tabular}{|c|c|c|}
\hline Parameter & Value & Reference \\
\hline $\mathbf{m}_{\mathbf{c o 2}} / \mathbf{M W} \mathbf{~ k g / s )}$ & 0,1 & {$[18]$} \\
\hline $\mathbf{f}_{\mathbf{0}}$ & 0,15 & {$[18]$} \\
\hline $\mathbf{P}$ (bar) & 1 & {$[18]$} \\
\hline $\mathbf{T}(\mathbf{o} \mathbf{C})$ & 650 & {$[18]$} \\
\hline $\mathbf{h}$ (nm) & 50 & {$[18]$} \\
\hline $\mathbf{K}_{\mathbf{s}}\left(\mathbf{m}^{4} / \mathbf{m o l} \cdot \mathbf{s}\right)$ & $4 \times 10^{-10}$ & \\
\hline
\end{tabular}

As seen in Figs. 7 and 8, the model proposed in this paper yield results which are less sensitive than those obtained from the reference model [18] to changes in the solids recirculation flow rate $\left(F_{R}\right)$ and the flow rate of fresh limestone introduced in the cycle $\left(F_{0}\right)$. On the other hand, for fixed values of $F_{0}$, increasing the solids inventory in

the carbonator yields a significant increase of the capture efficiency as a result of having considered the enhanced conversion in the diffusive phase. According to the reference model [18], increasing the solids inventory over a certain value does not lead to an increase of the carbonation efficiency despite it has not reached the maximum attainable value $(\approx 0,92)$ according to the inlet and equilibrium $\mathrm{CO}_{2}$ concentration for the carbonation reaction at $650^{\circ} \mathrm{C}$. This would be the maximum capture efficiency achievable if the solids had fully reacted, which is not 
theoretically allowed if carbonation in the diffusion controlled phase is fully neglected as assumed in previous modelling works [18]. In the reference model [18] the active fraction of solids drops significantly after a short time once the kinetic controlled phase is ended. In contrast, the solids are considered to remain active for a long time in the proposed model in the present work as long as the subsequent carbonation in the diffusion controlled phase is

5 taking place.

Figures 7 and 8 demonstrate that our model predicts a greater capture efficiency for longer residence times of the particles in the carbonator. For example, Fig. (8) shows that for a ratio $F_{R} / F_{C O 2}=5$, and a solids inventory of about $200 \mathrm{~kg} / \mathrm{MW}$, the proposed model predicts a higher capture efficiency than the reference model [18]. Figure 9 shows the capture efficiency calculated as a function of the residence time in the carbonator using $F_{R} / F_{C O 2}=5$ and $F_{0} / F_{C O 2}=0.01$ and varying the value of solids inventory, which changes the residence time $\tau$ (Eq. (13)). This figure shows also the ratio of the carbonation efficiency in the kinetic controlled phase to that in the diffusion controlled phase (right axis).

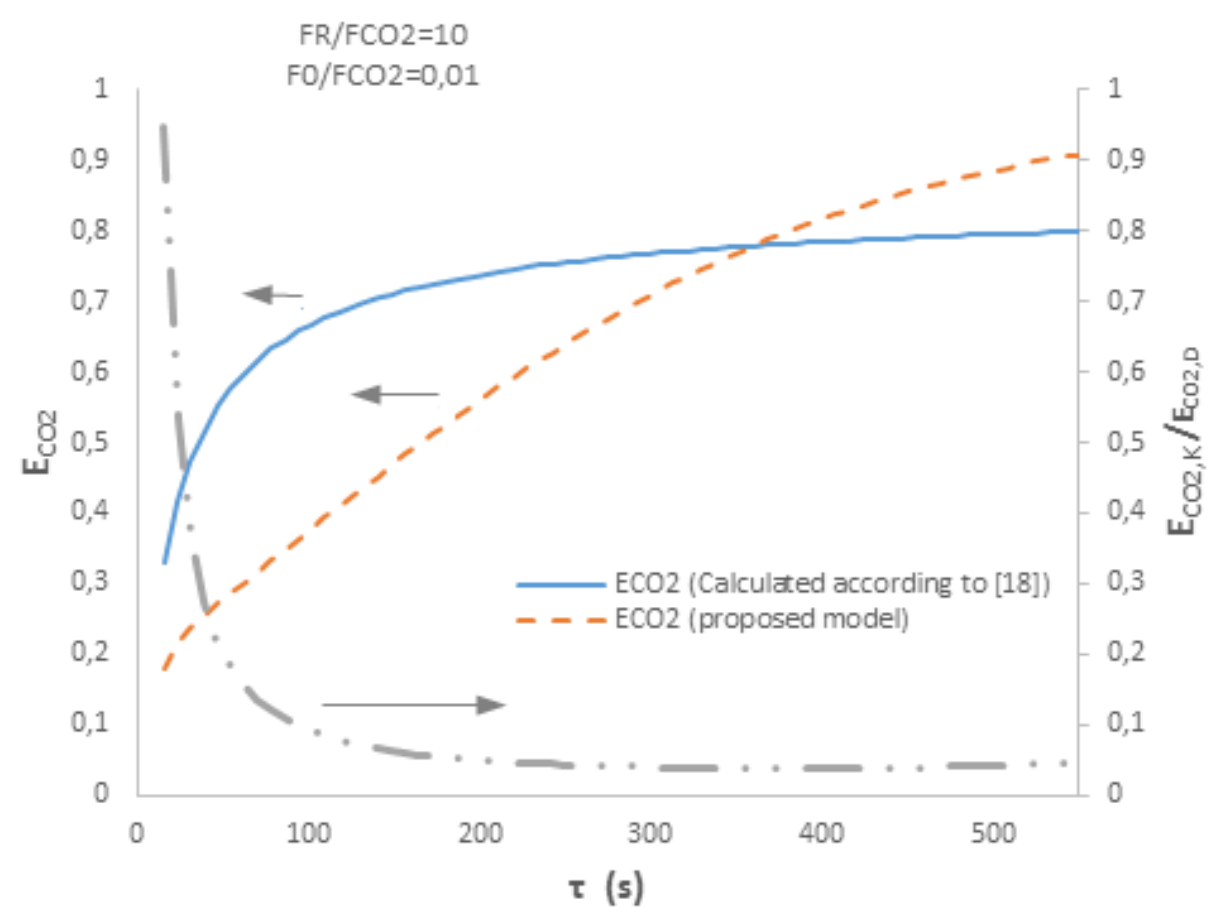

Figure 9: -Left axis: Carbonation efficiency as a function of the residence time in the reactor (modifying the solids inventory, Eq. (13)). - Right axis: Ratio of $\mathrm{CO}_{2}$ capture efficiency in the kinetic controlled phase to carbonation efficiency in the diffusion controlled phase as a function of residence time. Calculations are made for fixed values of $F_{R} / F_{C_{02}}$ and $\mathrm{F}_{0} / \mathrm{F}_{\mathrm{CO} 2}$ as indicated

Figure 9 shows that, according to the reference model [18], the capture efficiency is not improved further after a 
phase) diminishes with time quickly. On the other hand, the capture efficiency is further improved by taking into account enhanced conversion in the diffusive phase as shown by the results obtained from the model proposed. As can be seen in Fig. 9 the capture efficiency in the diffusive phase $\left(E_{C O 2, D}\right)$ becomes the major contribution to the total carbonation efficiency just after tens of seconds. Besides, the capture efficiency continues to increase with 5 the residence time and may reach a rather high value at residence times above $500 \mathrm{~s}$.

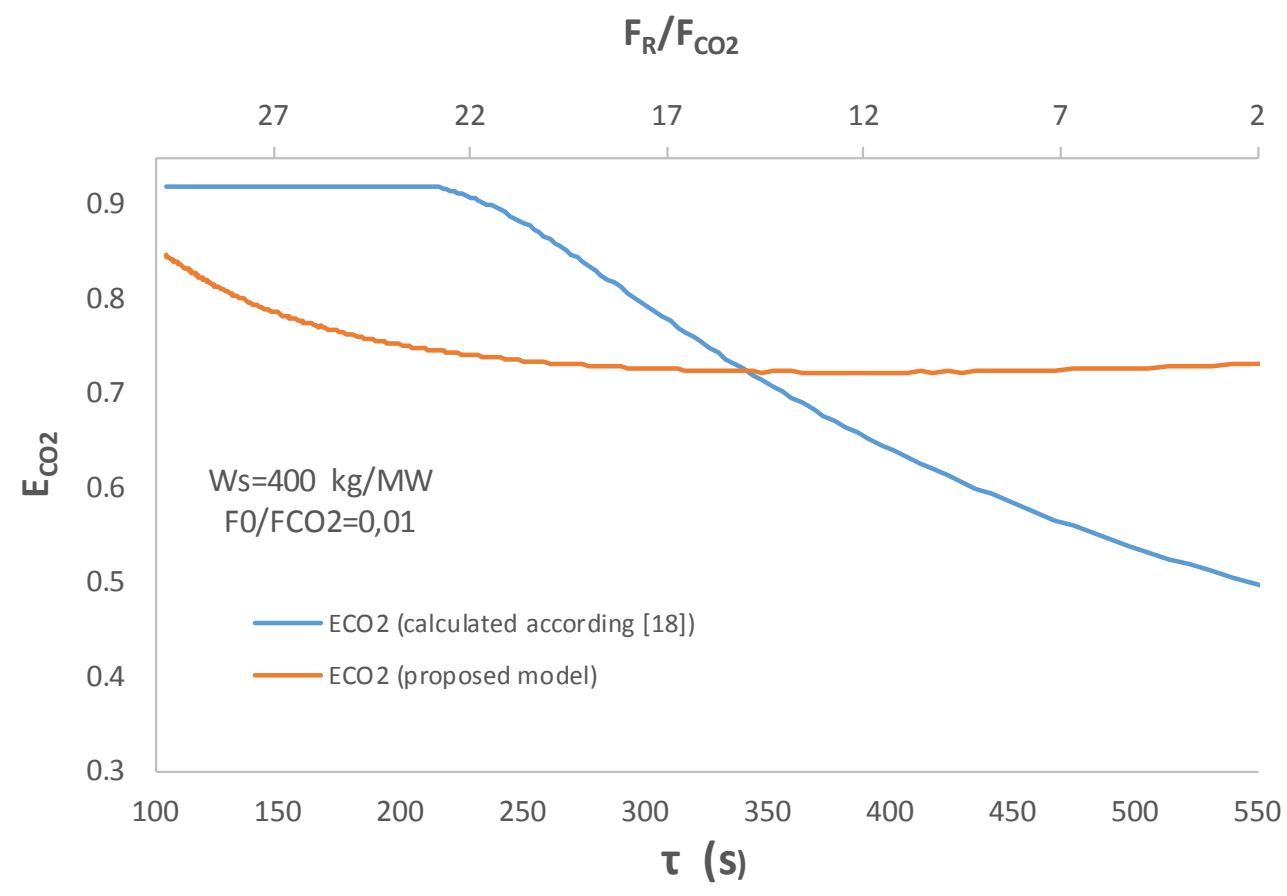

Figure 10: Carbonation efficiency as a function of the residence time in the carbonator, which is varied by changing the 10 $\mathrm{F}_{\mathrm{R}} / \mathrm{F}_{\mathrm{CO} 2}$ ratio (upper horizontal axis). Calculations made for fixed values of $\mathrm{W}_{\mathrm{s}}$ and $\mathrm{F}_{\mathrm{O}} / \mathrm{FcO}_{\mathrm{C}}$ as indicated.

Figure 10 shows the effect on the capture efficiency of increasing the residence time (horizontal bottom axis) by decreasing the flow rate of recirculated solids between the reactors ( $F_{R}$, horizontal top axis) while maintaining fixed a value for the solids inventory. As may be observed, by taking into account conversion in the diffusive phase, the capture efficiency is notably increased by increasing the value of the average residence time of the particles $(\tau)$ while the solids recirculation flow rate is decreased (with a constant value of solids inventory in the carbonator). An additional benefit of reducing the recirculation flow rate can be that the solids activity would be extended for longer times since the frequency of calcinations is reduced, which would serve to minimize the makeup flow of fresh limestone needed. 


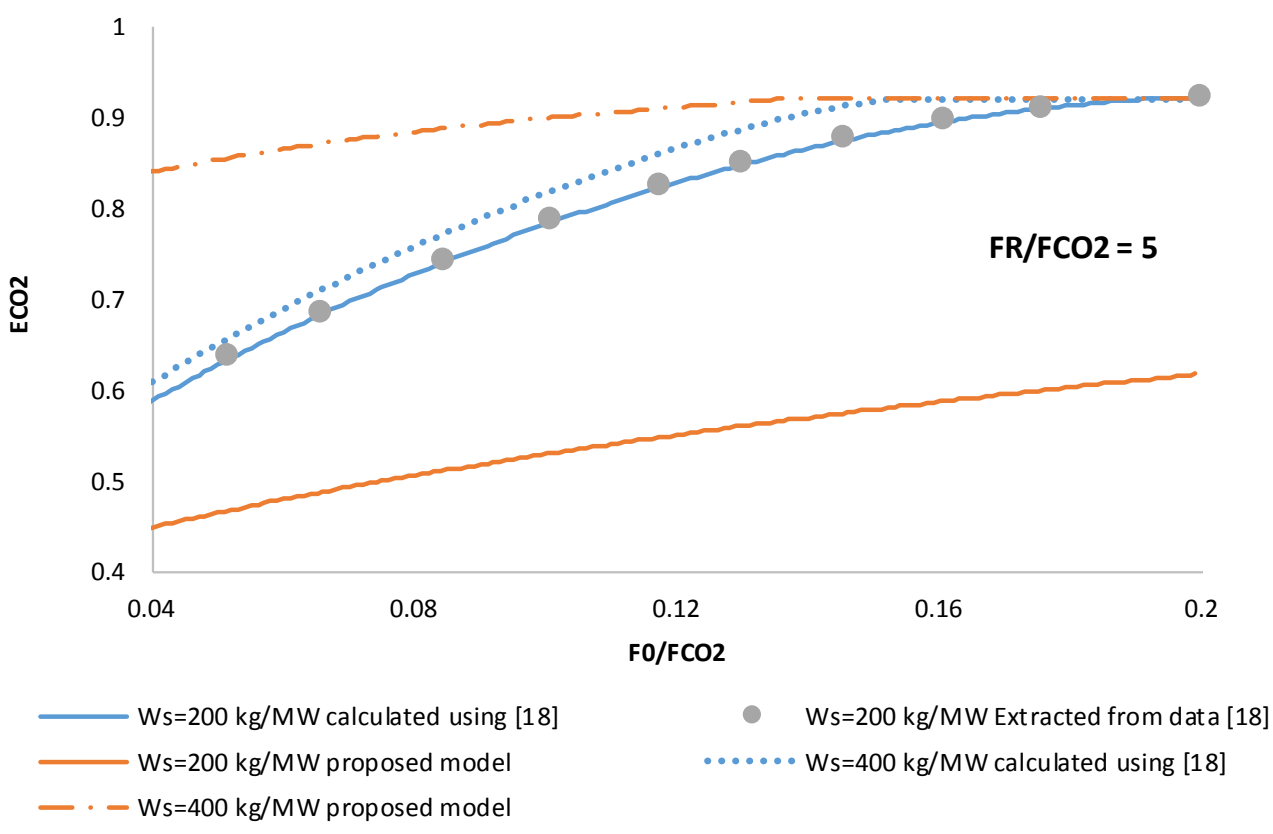

Figure 11: Capture efficiency as a function of the ratio of makeup flow rate to $\mathrm{CO}_{2}$ flow rate $\left(\mathrm{F}_{0} / \mathrm{F}_{\mathrm{CO}}\right)$ at different solid inventories $\left(W_{s}\right)$ and ratios of the recirculation flow rate to $\mathrm{CO}_{2}$ flow rate $\left(\mathrm{F}_{\mathrm{R}} / \mathrm{F}_{\mathrm{CO} 2}\right)$. Results from the proposed model in this work are compared with results from the model presented in a previous work [18].

The results plotted in Figure 11 correspond to simulations in which the solids recirculation flow rate $F_{R}$ is kept fixed while the flow rate of limestone makeup into the calciner $\left(F_{0}\right)$ is varied. Interestingly, it is seen that high capture efficiency may be achieved by operating with low values of $F_{0}$ when $W_{s}$ is increased as a consequence of having extended the lifetime of the particles that remain active in the carbonator by virtue of diffusive carbonation. We must note, however, that neither sulphation nor ashes, which will reduce the activity of the sorbent, have been considered in the model. An additional makeup flow of fresh limestone will have to be employed in practice due to irreversible sulphation and deactivation by ashes as reported in many studies $[7,16,25,45-47]$.

Let us now compare predicted results by the proposed model with experimental results obtained from pilot-scale tests. Capture efficiency obtained in pilot-scale tests is usually reported as a function of an "active space time" $15[13,14,28]$, which is expressed as the product of the residence time times the fraction of active particles reacting in the fast stage and the average conversion in this stage $\tau_{a}=\tau f_{a} X_{a v e, K}$. Taking into account also carbonation in the diffusive phase, $\tau_{a}$ would be defined in our model as [28]

$$
\tau_{a}=\tau\left(f_{a} X_{a v e, K}+\left(1-f_{a}\right) X_{a v e, D}\right)
$$

Table 3 shows the operating conditions used in the simulations whose results are illustrated in Figure 12 . This figure shows experimental values of the carbonation efficiency obtained from the pilot-scale INCAR plant and reported in 
$[14,19,28]$. The operating conditions used in the simulations have been chosen as representatives of those reported at INCAR pilot-scale tests $[14,28]$.

Table 3: Operating conditions used in the simulations whose results are plotted in figure 12

\begin{tabular}{|l|l|l|l|l|}
\hline \multicolumn{5}{|c|}{$\mathrm{V}_{\text {gas }}=1,15\left(\mathrm{~m}^{3} / \mathrm{s}\right) / \mathrm{MW}$} \\
\hline \multicolumn{5}{|c|}{$\mathrm{f}_{0}=0,15$} \\
\hline & Conditions 1 & Conditions 2 & Conditions 3 & Conditions 4 \\
\hline & 5 & 10 & 5 & 10 \\
\hline FR/FCO2 & 0,1 & 0,1 & 0,01 & 0,01 \\
\hline F0/FCO2 & $0,100-800$ & \\
\hline
\end{tabular}

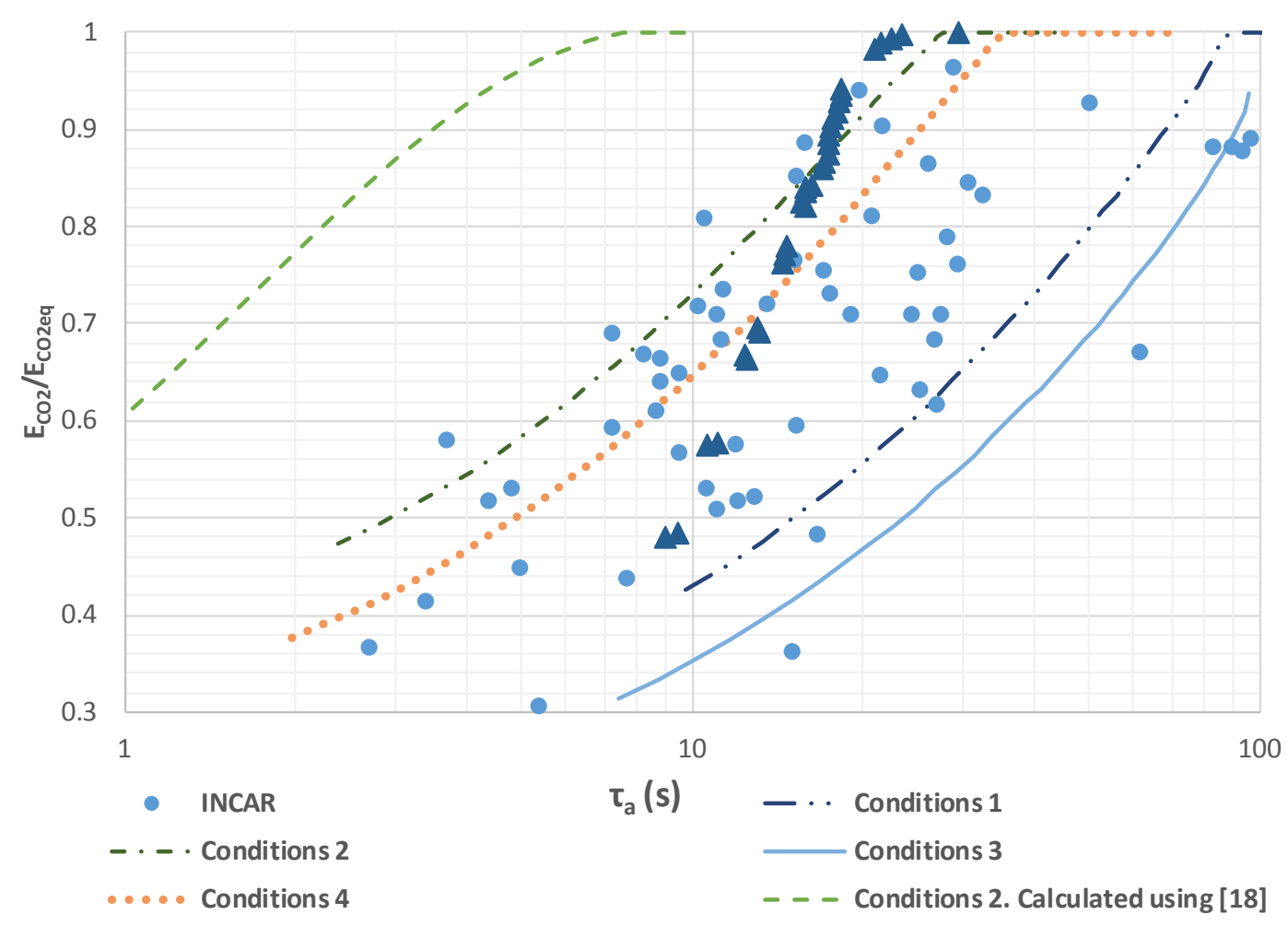

$\Delta \quad$ Model proposed in [16]

Figure 12: Normalized capture efficiency as a function of the active space time. Results obtained from the proposed model in this work using diverse operating conditions (displayed in Table 3) are compared with results obtained from previous models [16] [18] and with experimental data reported from pilot-scale INCAR tests [28].

As can be seen in Figure 12 the model developed in the present work provides results that conform better to experimental results as compared to the results obtained from the previously proposed model by Alonso et al. [18], which predict higher capture efficiencies than the experimental ones. Results extracted from a model proposed by Romano [16], which takes into account the effect of ash, irreversible sulphation, and fluidized bed dynamics have been also plotted in Fig. 12. Romano also neglects carbonation in the diffusion phase and uses CaO multicyclic 
conversion data derived from tests in which calcination was carried out under low $\mathrm{CO}_{2}$ partial pressure [33]. Although Romano's model results fit to the experimental results within the data scatter, it may be seen that the carbonation efficiency is predicted to increase with the active residence time at a higher rate than the experimentally observed trend (Fig 14). Arguably, the key point enabling our model to reproduce the experimental

5 trend is to include $\mathrm{CaO}$ conversion in the diffusion phase, which brings about a non-negligible contribution to the carbonation efficiency. As pointed out by Charitos et al. [42], the particle fraction that would be reacting in the diffusion regime can be much higher than the active fraction reacting in the fast regime. Moreover, as reviewed in the introduction of the present work, carbonation in the diffusion regime is greatly enhanced when calcination is carried out under high $\mathrm{CO}_{2}$ concentration. The new model takes into account these relevant aspects in order to predict more realistic values for the capture efficiency. A subject for further work would be to incorporate into our model the effect of irreversible sulphation, ashes and fluidized bed dynamics.

\section{Conclusions}

Carbonator models formulated until now are based on lab-scale multicyclic $\mathrm{CaO}$ conversion results carried out by regenerating $\mathrm{CaO}$ under low $\mathrm{CO}_{2}$ partial pressure. Under these unrealistic conditions, carbonation in the kinetically controlled fast phase prevails on diffusive carbonation. Thus, these models neglect further carbonation of the particles once the fast carbonation stage is ended. However, calcination under realistic $\mathrm{CaO}$ regeneration conditions, involving a high $\mathrm{CO}_{2}$ partial pressure in the calcination environment, leads to a significant enhancement of $\mathrm{CaO}$ carbonation in the diffusion controlled phase as compared to the kinetically controlled fast phase, which is severely hindered. The new model proposed in this work is based on lab-scale multicyclic $\mathrm{CaO}$ conversion results in which calcination is carried out under high $\mathrm{CO}_{2}$ partial pressure as expected in practice. Given the extraordinary relevance of carbonation in the diffusive phase observed under these realistic conditions, the model incorporates in the calculation of the capture efficiency this stage of carbonation. Thus, the particles are considered to remain active in the carbonator beyond the kinetically controlled carbonation phase, which is quite reduced. A main conclusion from the simulation results is that the capture efficiency is improved by increasing the residence time in the carbonator. Thus, for typical inventories of solids in the carbonator used in previous models, we see that the molar flow rate of $\mathrm{CaO}$ recirculated can be substantially decreased while a high capture efficiency is obtained. By increasing the residence time of the particles in the carbonator, deactivation due to sintering in the calciner would 
be mitigated. Furthermore, a smaller flow of recirculated solids would allow reducing energy penalties in the operation of power plants since the amount of heat required for calcination would be lowered and the energy necessary for material transport would be also reduced. In addition, a prolonged carbonation during extended residence times in the carbonator will allow extracting more heat from the reaction exothermicity. In a future work

5 we plan to improve the proposed model by taking into account other aspects that will affect the carbonation efficiency at practice such as irreversible sulphation, deactivation by ashes and the effect of fluidization dynamics.

\section{Acknowledgements}

This work was supported by the Andalusian Regional Government Junta de Andalucia (contract FQM-5735), Spanish Government Agency Ministerio de Economia y Competitividad (contract CTQ2014-52763-C2-2-R).

\section{Notation}

\begin{tabular}{|c|c|c|c|}
\hline A & carbonator section, $\mathrm{m}^{2}$ & $\mathrm{r}_{\mathrm{N}, \mathrm{K}}$ & $\begin{array}{l}\text { particle reaction rate in the kinetic } \\
\text { regime, } \mathrm{s}^{-1}\end{array}$ \\
\hline $\mathrm{C}_{\mathrm{CO} 2}$ & average $\mathrm{CO} 2$ concentration, $\mathrm{mol} / \mathrm{m}^{3}$ & $S_{\text {ave,k }}$ & average reaction available surface, $\mathrm{m}^{-1}$ \\
\hline $\mathrm{C}_{\mathrm{CO}, \mathrm{eq}}$ & equilibrium concentration of $\mathrm{CO} 2, \mathrm{~mol} / \mathrm{m}^{3}$ & $\mathrm{~S}_{\mathrm{N}}$ & $\begin{array}{l}\text { reaction available surface in the } \mathrm{N} \text { cycle, } \\
\mathrm{m} 2 / \mathrm{m} 3\end{array}$ \\
\hline$D_{\text {eff }}$ & intrinsic diffusion constant, $\mathrm{m}^{3} /(\mathrm{mol} \cdot \mathrm{s})$ & $\mathrm{T}$ & temperature $(\stackrel{\circ}{ } \mathrm{C})$ \\
\hline$D^{*}{ }_{\text {eff }}$ & equivalent diffusion constant, $\mathrm{m}^{3} /(\mathrm{mol} \cdot \mathrm{s})$ & $\mathrm{t}$ & time, $s$ \\
\hline $\mathrm{E}_{\mathrm{CO} 2}$ & carbon capture efficiency & $t_{k}$ & $\begin{array}{l}\text { characteristic time at which kinetic } \\
\text { phase end, } s\end{array}$ \\
\hline $\mathrm{E}_{\mathrm{CO} 2 \text {,eq }}$ & maximum carbon capture efficiency & $t_{\max }$ & Particle residence time in carbonator, $\mathrm{s}$ \\
\hline $\mathrm{E}_{\mathrm{CO} 2, \mathrm{D}}$ & $\begin{array}{l}\text { carbon capture efficiency in the diffusion } \\
\text { regime }\end{array}$ & $V_{\text {gas }}$ & $\begin{array}{l}\text { volume flow rate per } \mathrm{MW} \text { of a typical } \\
\text { power plant in flue gas entering the } \\
\text { carbonator, } \mathrm{m}^{3} / \mathrm{s}\end{array}$ \\
\hline $\mathrm{E}_{\mathrm{CO}, \mathrm{K}}$ & carbon capture efficiency in the kinetic regime & $\mathrm{V}_{\mathrm{M}, \mathrm{CaCO}}$ & molar volume, $\mathrm{m}^{3} / \mathrm{mol}$ \\
\hline$f_{0}$ & inlet molar fraction of $\mathrm{CO}_{2}$ & $\mathrm{~W}_{\mathrm{s}}$ & $\begin{array}{l}\text { solid inventory in the carbonator per } \\
\text { MW of a typical power plant, } \mathrm{kg}\end{array}$ \\
\hline$f_{a}$ & $\begin{array}{l}\text { volumetric fraction of } \mathrm{CaO} \text { that reacts in the } \\
\text { kinetic reaction regime }\end{array}$ & $W_{s, c}$ & $\begin{array}{l}\text { solid inventory in the calciner per MW } \\
\text { of a typical power plant, } \mathrm{kg}\end{array}$ \\
\hline$f_{e}$ & equilibrium molar fraction of $\mathrm{CO}_{2}$ & $x$ & carbonation degree of a $\mathrm{CaO}$ particle \\
\hline $\mathrm{F}_{0}$ & mole flow of fresh makeup limestone, $\mathrm{mol} / \mathrm{s}$ & $X_{\text {ave }}$ & average conversion of the sorbent \\
\hline $\mathrm{F}_{\mathrm{CO} 2}$ & $\begin{array}{l}\text { mole flow of } \mathrm{CO}_{2} \text { in flue gas entering the } \\
\text { carbonator }\end{array}$ & $X_{\text {ave }, \mathrm{D}}$ & $\begin{array}{l}\text { average conversion of the sorbent in } \\
\text { the diffusion phase }\end{array}$ \\
\hline $\mathrm{F}_{\mathrm{CO} 2, \mathrm{cal}}$ & $\begin{array}{l}\text { mole flow of } \mathrm{CO}_{2} \text { originating in the calciner, } \\
\mathrm{mol} / \mathrm{s}\end{array}$ & $X_{\text {ave, } \mathrm{K}}$ & $\begin{array}{l}\text { average conversion of the sorbent in } \\
\text { the kinetic phase }\end{array}$ \\
\hline $\mathrm{F}_{\mathrm{p}}$ & mole flow of solids purge in the calciner, $\mathrm{mol} / \mathrm{s}$ & $X_{\text {max,ave }}$ & $\begin{array}{l}\text { maximum average carbonation degree } \\
\text { of } \mathrm{CaO} \text { in the solid population }\end{array}$ \\
\hline $\mathrm{F}_{\mathrm{R}}$ & $\begin{array}{l}\text { mole flow of } \mathrm{CaO} \text { coming from the calciner, } \\
\mathrm{mol} / \mathrm{s}\end{array}$ & $X_{\text {max, ave, } \mathrm{D}}$ & $\begin{array}{l}\text { maximum average carbonation degree } \\
\text { of } \mathrm{CaO} \text { in the solid population in the } \\
\text { diffusion phase }\end{array}$ \\
\hline $\mathrm{h}$ & $\begin{array}{l}\text { thickness of the product layer of a sorbent } \\
\text { particle, } \mathrm{nm}\end{array}$ & $X_{\text {max,ave, }}$ & $\begin{array}{l}\text { maximum average carbonation degree } \\
\text { of } \mathrm{CaO} \text { in the solid population in the } \\
\text { kinetic phase }\end{array}$ \\
\hline
\end{tabular}




\begin{tabular}{|c|c|c|c|}
\hline$k_{s}$ & intrinsic kinetic constant $\mathrm{m}^{4} /(\mathrm{mol} \cdot \mathrm{s})$ & $X_{N}$ & $\begin{array}{l}\text { maximum carbonation degree of } \mathrm{CaO} \text { in } \\
\text { the } \mathrm{N} \text { cycle }\end{array}$ \\
\hline $\mathrm{T}_{0}$ & time of TGA multicyclic test, $\mathrm{s}$ & $X_{N D}$ & $\begin{array}{l}\text { maximum carbonation degree of } \mathrm{CaO} \text { in } \\
\text { the } \mathrm{N} \text { cycle in the diffusion phase }\end{array}$ \\
\hline $\mathrm{M}_{\mathrm{CaO}}$ & Molar mass of $\mathrm{CaCO}_{3}, \mathrm{~g} / \mathrm{mol}$ & $\mathrm{X}_{\mathrm{NK}}$ & $\begin{array}{l}\text { maximum carbonation degree of } \mathrm{CaO} \text { in } \\
\text { the } \mathrm{N} \text { cycle in the kinetic phase }\end{array}$ \\
\hline $\mathrm{m}_{\mathrm{CO} 2}$ & $\begin{array}{l}\text { volume flow rate per } \mathrm{MW} \text { of a typical power } \\
\text { plant of } \mathrm{CO}_{2} \text { in flue gas entering the carbonator, } \\
\mathrm{m}^{3} / \mathrm{s}\end{array}$ & $X_{r}$ & $\begin{array}{l}\text { residual conversion capacity of a } \\
\text { sorbent particle }\end{array}$ \\
\hline $\mathrm{N}$ & calcination-carbonation cycles & K & $\begin{array}{l}\text { deactivation constant of a sorbent } \\
\text { particle }\end{array}$ \\
\hline $\mathrm{N}_{\mathrm{Ca}}$ & mol of $\mathrm{Ca}$ in the carbonator, $\mathrm{mol}$ & $\Phi_{\mathrm{N}}$ & particle fraction in the $\mathrm{N}$ cycle \\
\hline$P$ & pressure (bar) & $\rho_{\mathrm{CaO}}$ & $\mathrm{CaO}$ density, $\mathrm{g} / \mathrm{m} 3$ \\
\hline$r_{\text {ave, }, \mathrm{D}}$ & average reaction rate in the diffusion regime, $\mathrm{s}^{-1}$ & $\rho_{g}$ & density of gas phase, $\mathrm{g} / \mathrm{m} 3$ \\
\hline$r_{\text {ave }, \mathrm{K}}$ & average reaction rate in the kinetic regime, $\mathrm{s}^{-1}$ & $\tau$ & $\begin{array}{l}\text { average residence time in the } \\
\text { carbonator, } s\end{array}$ \\
\hline $\mathbb{N},[$ & particle reaction rate in the diffusion regime, $\mathrm{s}^{-1}$ & $\tau_{a}$ & active space time of the carbonator, $\mathrm{s}$ \\
\hline
\end{tabular}

\section{References}

[1] Change WGI of the IP on C. IPCC,2005: Special Report on CARBON DIOXIDE CAPTURE AND STORAGE. 2005.

[2] Romeo LM, Lara Y, Lisbona P, Martínez A. Economical assessment of competitive enhanced limestones for $\mathrm{CO}_{2}$ capture cycles in power plants. Fuel Process Technol 2009;90:803-11. doi:10.1016/j.fuproc.2009.03.014.

10 [3] Dean $\mathrm{CC}$, Blamey J, Florin $\mathrm{NH}$, Al-Jeboori MJ, Fennell PS. The calcium looping cycle for $\mathrm{CO}_{2}$ capture from power generation, cement manufacture and hydrogen production. Chem Eng Res Des 2011;89:836-55. doi:10.1016/j.cherd.2010.10.013.

[4] Martínez A, Lara Y, Lisbona P, Romeo LM. Energy penalty reduction in the calcium looping cycle. Int J Greenh Gas Control 2012;7:74-81. doi:10.1016/j.ijggc.2011.12.005.

15 [5] Cormos C-C. Economic evaluations of coal-based combustion and gasification power plants with postcombustion $\mathrm{CO}_{2}$ capture using calcium looping cycle. Energy 2014;78:665-73.

doi:10.1016/j.energy.2014.10.054.

[6] Wang W, Ramkumar S, Wong D, Fan LS. Simulations and process analysis of the carbonation-calcination reaction process with intermediate hydration. Fuel 2012;92:94-106. doi:10.1016/j.fuel.2011.06.059.

[7] Manovic V, Anthony EJ. Competition of sulphation and carbonation reactions during looping cycles for $\mathrm{CO} 2$ capture by cao-based sorbents. J Phys Chem A 2010;114:3997-4002. doi:10.1021/jp910536w.

[8] Romano MC, Martínez I, Murillo R, Arstad B, Blom R, Ozcan DC, et al. Process simulation of Ca-looping processes: Review and guidelines. Energy Procedia 2013;37:142-50. doi:10.1016/j.egypro.2013.05.095.

[9] Kim K, Kim D, Park Y, Soon K. International Journal of Greenhouse Gas Control A solid sorbent-based multistage fluidized bed process with inter-stage heat integration as an energy efficient carbon capture process. Int J Greenh Gas Control 2014;26:135-46. doi:10.1016/j.ijggc.2014.03.012. 
[10] Ylätalo J, Ritvanen J, Tynjälä T, Hyppänen T. Model based scale-up study of the calcium looping process. Fuel 2014;115:329-37. doi:10.1016/j.fuel.2013.07.036.

[11] Ylätalo J, Parkkinen J, Ritvanen J, Tynjälä T, Hyppänen T. Modeling of the oxy-combustion calciner in the post-combustion calcium looping process. Fuel 2013;113:770-9. doi:10.1016/j.fuel.2012.11.041.

5 [12] Vorrias I, Atsonios K, Nikolopoulos A, Nikolopoulos N, Grammelis P, Kakaras E. Calcium looping for $\mathrm{CO}_{2}$ capture from a lignite fired power plant. Fuel 2013;113:826-36. doi:10.1016/j.fuel.2012.12.087.

[13] Dieter $\mathrm{H}$, Bidwe AR, Varela-duelli G, Charitos A, Hawthorne C. Development of the calcium looping $\mathrm{CO}_{2}$ capture technology from lab to pilot scale at IFK, University of Stuttgart. Fuel 2014;127:23-37. doi:10.1016/j.fuel.2014.01.063.

[14] Arias B, Diego ME, Abanades JC, Lorenzo M, Diaz L, Martínez D, et al. Demonstration of steady state $\mathrm{CO}_{2}$ capture in a 1.7MWth calcium looping pilot. Int J Greenh Gas Control 2013;18:237-45. doi:10.1016/j.ijggc.2013.07.014.

[15] Lasheras A, Ströhle J, Galloy A, Epple B. Carbonate looping process simulation using a 1D fluidized bed model for the carbonator. Int J Greenh Gas Control 2011;5:686-93. doi:10.1016/j.ijggc.2011.01.005.

[16] Romano MC. Modeling the carbonator of a Ca-looping process for $\mathrm{CO}_{2}$ capture from power plant flue gas. Chem Eng Sci 2012;69:257-69. doi:10.1016/j.ces.2011.10.041.

[17] Romano M, Martínez I, Murillo R, Arstad B. Guidelines for modeling and simulation of Ca-looping processes. Prepared for the European Energy Research Alliance. SintefNo 2012.

[18] Alonso M, Rodríguez N, Grasa G, Abanades JC. Modelling of a fluidized bed carbonator reactor to capture $\mathrm{CO}_{2}$ from a combustion flue gas. Chem Eng Sci 2009;64:883-91. doi:10.1016/j.ces.2008.10.044.

[19] Alonso M, Rodríguez N, González B, Grasa G, Murillo R, Abanades JC. Carbon dioxide capture from combustion flue gases with a calcium oxide chemical loop. Experimental results and process development. Int J Greenh Gas Control 2010;4:167-73. doi:10.1016/j.ijggc.2009.10.004.

[20] Alonso M, Diego ME, Pérez C, Chamberlain JR, Abanades JC. Biomass combustion with in situ $\mathrm{CO}_{2}$ capture by $\mathrm{CaO}$ in a 300kWth circulating fluidized bed facility. Int J Greenh Gas Control 2014;29:142-52. doi:10.1016/j.ijggc.2014.08.002.

[21] Ströhle J, Junk M, Kremer J, Galloy A, Epple B. Carbonate looping experiments in a 1 MWth pilot plant and model validation. Fuel 2014;127:13-22. doi:10.1016/j.fuel.2013.12.043.

[22] Valverde JM, Sanchez-Jimenez PE, Perez-Maqueda L a. Limestone Calcination Nearby Equilibrium: Kinetics, CaO Crystal Structure, Sintering and Reactivity. J Phys Chem C 2015;119:1623-41. doi:10.1021/jp508745u.

[23] Coppola A, Scala F, Salatino P, Montagnaro F. Fluidized bed calcium looping cycles for $\mathrm{CO}_{2}$ capture under oxy-firing calcination conditions: Part 1. Assessment of six limestones. Chem Eng J 2013;231:537-43. doi:10.1016/j.cej.2013.07.113.

[24] Manovic V, Charland JP, Blamey J, Fennell PS, Lu DY, Anthony EJ. Influence of calcination conditions on carrying capacity of CaO-based sorbent in $\mathrm{CO}_{2}$ looping cycles. Fuel 2009;88:1893-900. doi:10.1016/j.fuel.2009.04.012.

[25] J.M. Cordero MA. Modelling of the kinetics of sulphation of $\mathrm{CaO}$ particles under $\mathrm{CaL}$ reactor conditions. Fuel 2015;150:501-11. doi:10.1016/j.fuel.2015.02.075. 
[26] Valverde JM. Relevant Influence of Limestone Crystallinity on $\mathrm{CO}_{2}$ Capture in The Ca-Looping Technology at Realistic Calcination Conditions 2014.

[27] Martínez I, Grasa G, Murillo R, Arias B, Abanades JC. Modelling the continuous calcination of $\mathrm{CaCO}_{3}$ in a Calooping system. Chem Eng J 2013;215-216:174-81. doi:10.1016/j.cej.2012.09.134.

5 [28] Charitos A, Rodríguez N, Hawthorne C, Alonso M, Zieba M, Arias B, et al. Experimental Validation of the Calcium Looping $\mathrm{CO}_{2}$ Capture Process with Two Circulating Fluidized Bed Carbonator Reactors. Ind Eng Chem Res 2011;50:9685-95. doi:10.1021/ie200579f.

[29] Shimizu T, Hirama T, Hosoda H, Kitano K, Inagaki M, Tejima K. A Twin Fluid-Bed Reactor for Removal of $\mathrm{CO}_{2}$ from Combustion Processes. Chem Eng Res Des 1999;77:62-8. doi:10.1205/026387699525882.

[30] Abanades JC. The maximum capture efficiency of $\mathrm{CO}_{2}$ using a carbonation/calcination cycle of $\mathrm{CaO} / \mathrm{CaCO}_{3}$. Chem Eng J 2002;90:303-6. doi:10.1016/S1385-8947(02)00126-2.

[31] Abanades JC, Alvarez D. Conversion limits in the reaction of $\mathrm{CO}_{2}$ with lime. Energy and Fuels 2003;17:30815. doi:10.1021/ef020152a.

[32] Borgwardt RH. Calcium oxide sintering in atmospheres containing water and carbon dioxide. Ind Eng Chem Res 1989;28:493-500. doi:10.1021/ie00088a019.

[33] Grasa GS, Abanades JC. $\mathrm{CO}_{2}$ Capture Capacity of $\mathrm{CaO}$ in Long Series of Carbonation/Calcination Cycles. Ind Eng Chem Res 2006;45:8846-51. doi:10.1021/ie0606946.

[34] Valverde JM. A model on the CaO multicyclic conversion in the Ca-looping process. Chem Eng J 2013;228:1195-206. doi:10.1016/j.cej.2013.05.023.

[35] Valverde JM, Sanchez-Jimenez PE, Perez-Maqueda $L$ a. Role of precalcination and regeneration conditions on postcombustion $\mathrm{CO}_{2}$ capture in the Ca-looping technology. Appl Energy 2014;136:347-56. doi:10.1016/j.apenergy.2014.09.052.

[36] Arias B, Abanades JC, Grasa GS. An analysis of the effect of carbonation conditions on CaO deactivation curves. Chem Eng J 2011;167:255-61. doi:10.1016/j.cej.2010.12.052.

25 [37] Mess D, Sarofim AF, Longwell JP. Product Layer Diffusion during the Reaction of Calcium Oxide with Carbon Dioxide. Energy \& Fuels 1999;13:999-1005. doi:10.1021/ef980266f.

[38] Bhatia SK, Perlmutter DD. Effect of the product layer on the kinetics of the carbon dioxide-lime reaction. AIChE J 1983;29:79-86. doi:10.1002/aic.690290111.

[39] Alvarez D, Abanades JC. Determination of the Critical Product Layer Thickness in the Reaction of CaO with CO 2. Ind Eng Chem Res 2005;44:5608-15. doi:10.1021/ie050305s.

[40] Li Z, Fang F, Xiao-yu T, Cai N. Effect of Temperature on the Carbonation Reaction of $\mathrm{CaO}$ with $\mathrm{CO}_{2}$. Energy and Fuels 2012;26:4607-16. doi:10.1021/ef300607z.

[41] Sun Z, Luo S, Qi P, Fan LS. lonic diffusion through Calcite ( $\mathrm{CaCO} 3$ ) layer during the reaction of $\mathrm{CaO}$ and $\mathrm{CO}_{2}$. Chem Eng Sci 2012;81:164-8. doi:10.1016/j.ces.2012.05.042.

35 [42] Sanchez-Jimenez PE, Valverde JM, Perez-Maqueda L a. Multicyclic conversion of limestone at Ca-looping conditions: The role of solid-sate diffusion controlled carbonation. Fuel 2014;127:131-40.

doi:10.1016/j.fuel.2013.09.064. 
[43] Valverde JM, Sanchez-Jimenez PE, Perez-Maqueda $\mathrm{L}$ a. Calcium-looping for post-combustion $\mathrm{CO}_{2}$ capture. On the adverse effect of sorbent regeneration under $\mathrm{CO}_{2}$. Appl Energy 2014;126:161-71. doi:10.1016/j.apenergy.2014.03.081.

[44] Grasa GS, Abanades JC, Alonso M, González B. Reactivity of highly cycled particles of $\mathrm{CaO}$ in a carbonation/calcination loop. Chem Eng J 2008;137:561-7. doi:10.1016/j.cej.2007.05.017.

[45] Symonds RT, Lu DY, Manovic V, Anthony EJ. Pilot-scale study of $\mathrm{CO}_{2}$ capture by CaO-based sorbents in the presence of steam and $\mathrm{SO}_{2}$. Ind Eng Chem Res 2012;51:7177-84. doi:10.1021/ie2030129.

[46] Ryu HJ, Grace JR, Lim CJ. Simultaneous $\mathrm{CO}_{2} / \mathrm{SO}_{2}$ capture characteristics of three limestones in a fluidizedbed reactor. Energy and Fuels 2006;20:1621-8. doi:10.1021/ef050277q.

10 [47] Sun P, Grace JR, Lim CJ, Anthony EJ. Removal of $\mathrm{CO}_{2}$ by Calcium-Based Sorbents in the Presence of $\mathrm{SO}_{2}$. Energy \& Fuels 2007;21:163-70. doi:10.1021/ef060329r.

[48] Tian S, Jiang J, Li K, Yan F, Chen X. Performance of steel slag in carbonation-calcination looping for $\mathrm{CO}_{2}$ capture from industrial flue gas. RSC Adv 2014;4:6858. doi:10.1039/c3ra47426g.

[49] Valverde JM, Sanchez-Jimenez PE, Perez-Maqueda $\mathrm{L}$ a. High and stable $\mathrm{CO}_{2}$ capture capacity of natural limestone at Ca-looping conditions by heat pretreatment and recarbonation synergy. Fuel 2014;123:7985. doi:10.1016/j.fuel.2014.01.045. 